\title{
Implications of Female Sex on Stroke Risk Factors, Care, Outcome and Rehabilitation: An Asian Perspective
}

\author{
Prachi Mehndiratta ${ }^{a}$ Mohammad Wasay ${ }^{b}$ Man Mohan Mehndiratta ${ }^{c}$ \\ a Vascular Neurology Fellow, McKim Hall, University of Virginia, Charlottesville, Va., USA; ${ }^{b}$ Department of Neurology, \\ Aga Khan University, Karachi, Pakistan; ' ${ }^{C}$ epartment of Neurology, Janakpuri Superspeciality Hospital, Janakpuri, \\ New Delhi, India
}

\section{Key Words}

Stroke in women · Stroke risk factors · Stroke therapy ·

Stroke outcome $\cdot$ Stroke rehabilitation

\begin{abstract}
Background: Stroke affects 16.9 million people annually and the greatest burden of stroke is in low- and middle-income countries, where $69 \%$ of all strokes occur. Stroke risk factors, mortality and outcomes differ in developing countries as compared to the developed world. We performed a literature review of 28 articles pertaining to epidemiology of stroke in Asian women, stroke risk factors, gender-related differences, and stroke outcomes. Summary: Asian women differ from women worldwide due to differences in stroke awareness, risk factor profile, stroke subtypes, and social issues that impact stroke care. While Asian men have a higher incidence of stroke as compared to women overall, the longand short-term outcomes in Asian women tend to be poorer. Both conventional and gender-specific risk factors contribute to stroke risk. Oral contraceptive use and addictions such as tobacco and alcohol are less prevalent among Asian women due to socio cultural differences. There is however, a much higher preponderance of pregnancy-related stroke and cardio-embolic stroke secondary to rheumatic heart disease and heavy use of chewing tobacco. The overall outcome is poor due to poor access to health care and lack of
\end{abstract}

resources. Key Messages: Our review exposed the gaps in our knowledge about stroke risk factors and differences in stroke care provided to Asian women. While there are sociocultural barriers that impede the provision of immediate care to these stroke patients, much needs to be done by way of prevention of recurrent stroke and treatment of risk factors.

(c) 2015 S. Karger AG, Basel

\section{Epidemiology}

Worldwide Stroke affects 16.9 million people annually and is the second most common cause of death $[1,2]$. The greatest burden of stroke is in low- and middle-income countries, where $69 \%$ of all strokes occur [3]. Asian countries constitute about $66 \%$ of world population and almost $70 \%$ of global stroke burden. Among Asian countries, South Asian countries (22\% of world population) are the ones that are hit the hardest. South Asian countries contribute greatly to stroke mortality with about $40 \%$ of global stroke deaths occurring here.

Age-adjusted prevalence of stroke in the Asian population ranges from 260 to 4,800 per 100,000 and for South Asian population ranges from 44 to 843 per 100,000 people [4]. Percent prevalence of stroke in South East Asia is estimated to be $14.6 \%$ and it accounts for 4.5 million out

\section{KARGER 125}

(c) 2015 S. Karger AG, Base

$1015-9770 / 15 / 0396-0302 \$ 39.50 / 0$

E-Mail karger@karger.com

www.karger.com/ced
Dr. Man Mohan Mehndiratta

President Asian Oceanian Association of Neurology

Janakpuri Superspeciality Hospital

C-2/B, Janakpuri, New Delhi 110058 (India)

E-Mail mmehndi@hotmail.com 
of 30.7 million cases worldwide. The epidemiology of stroke in the Asia-Pacific region differs from that in the western world. Two significant differences as highlighted by Woodward et al. [5] are (1) the higher incidence of cerebrovascular disease as compared to coronary heart disease and (2) a greater incidence of hemorrhagic stroke. Stroke in women and gender disparities are not well reported in the existing literature from Asia [6]. Much of the epidemiology is derived from mortality data. Women all over the world have lower stroke mortality than men similar to the stroke mortality in the United States [7, 8].

Physiological changes in women that contribute to ischemic stroke risk differ from those in men. Differences in immunity, hormonal changes and changes secondary to pregnancy and puerperium impact stroke type and outcome [9]. With the increasing population of women, the burden of stroke in women is bound to increase.

There is a paucity of well-designed studies describing the epidemiology of stroke in Asia especially related to stroke in women. Asian women differ from women worldwide due to differences in stroke awareness, risk factor profile, stroke subtypes, and social issues that impact stroke care.

The objective of this review article is to present a comprehensive understanding of stroke in Asian women and the factors that influence prevalence, risk and outcome. We compared this data to stroke in Asian men and European women with stroke (wherever available).

\section{Methods}

We performed a literature review searching PubMed, Google Scholar, and the University of Virginia Health Science Library Journal database, and applying the following key words in various combinations - stroke, ischemic stroke, hemorrhage, women, pregnancy, puerperium, cerebral venous thrombosis, China, Japan, India, Iran, Singapore, Thailand, and Asia. A total of 65 articles pertaining to epidemiology of stroke, stroke risk factors in women, gender-related differences, and outcomes were selected for review. Only articles published in English language were selected and both longitudinal and cross-sectional studies were reviewed.

\section{Results}

\section{Incidence and Prevalence}

Table 1 provides a comparison of age-adjusted stroke incidence between some Asian and European countries. It is evident that Asian women have a higher incidence as compared to European men and women and lower inci-
Table 1. Age-adjusted incidence per 100,000 population

\begin{tabular}{lll}
\hline Country & Men & Women \\
\hline United Kingdom (2004-2006) [62] & $121(100-144)$ & $78(62-97)$ \\
France (2000-2006) [63] & $107(98-117)$ & $69(62-75)$ \\
Italy (2004-2005) [64] & $122(94-150)$ & $77(55-99)$ \\
India (2003-2005) [10] & $117(88-152)$ & $178(102-223)$ \\
India (2005) [65] & $163(122-204)$ & $115(83-147)$ \\
China (Beijing) 2000 [13] & $147(134-162)$ & $124(113-137)$ \\
China (Changsha) 2000 [13] & $190(175-207)$ & $119(108-132)$ \\
\hline
\end{tabular}

dence as compared to Asian men (except one study from India).

The annual incidence rate of first-ever stroke was 123.15 per 100,000 (men, 99.54 per 100,000 ; women, 149.49 per 100,000$)$ persons per year $(95 \%$ CI, $102.46-$ $232.50)$ in India. This study highlighted the higher rate of stroke in women as compared to men [10]. Ischemic stroke was more common than hemorrhagic stroke, classified on the basis of neuroimaging and it occurred in a 1.86-2.21:1 ratio. In the western world, where hemorrhage is less common, the ratio of ischemic to hemorrhagic stroke is 5:1 [11].

The incidence of first-ever and recurrent events in Chinese men and women were found to be 247 and 175 per 100,000, respectively. The highest rate of stroke was in patients over age 75 and men consistently had a greater stroke incidence than women [12]. Recent studies have demonstrated higher percentages of intracerebral hemorrhage (ICH) ascompared to ischemic stroke at 18.8$47.6 \%$. This is consistent with literature on stroke epidemiology from other parts of Asia [13, 14].

One study from Iran has demonstrated a rising incidence of stroke from $84.6 / 100,000$ to $103.23 / 100,000$ over a four-year period. About $51-53 \%$ of patients in the stroke registries from Iran are females; hence, stroke is slightly more common in this population. About $67.2-68.45 \%$ of all patients experienced an ischemic event, while intracerebral hemorrhage and subarachnoid hemorrhage were seen in $23.9-28.4 \%$ and in $2.9-4.4 \%$ patients, respectively $[15,16]$.

In the INTERSTROKE study by O' Donnell et al. [17] women comprised $36 \%$ of stroke cases from Southeast Asia and 33\% of stroke patients from India were women. The frequency of cerebral venous thrombosis among young women with stroke is high (up to 20\%). A study of 64 patients with stroke in pregnancy and postpartum period by Panagariya et al. [18] revealed that CVST was responsible for $40 \%$ of stroke cases stroke. Recent studies of hemorrhagic stroke from Taiwan highlight an incidence 
Table 2. Age-adjusted stroke mortality per 100,000 population

\begin{tabular}{lll}
\hline Country & Men & Women \\
\hline United Kingdom 2010 [66] & 22 & 23 \\
France 2009 [66] & 11 & 14 \\
USA 2007 [66] & 15 & 15 \\
Japan 2011 [66] & 11 & 17 \\
Singapore 2011 [66] & 68 & 66 \\
China 1994 [67] & $86(50-142)$ & $67(27-130)$ \\
China 1997 [12] & 66 & 58 \\
\hline 30-day stroke mortality & & \\
China 1997 [12] & $27 \%$ & $33 \%$ \\
India 2007 [10] & $38 \%$ & $43 \%$ \\
UK 2013 [68] & $8 \%$ & $12 \%$ \\
\hline
\end{tabular}

of pregnancy-related intracerebral hemorrhage at 10.531.4 per 100,000 deliveries [19]. This is in contrast to American and European studies that have found an $\mathrm{ICH}$ incidence of 4.6-6.1/100,000 deliveries [20,21]. There is a paucity of data regarding the incidence and prevalence of stroke in Asian women. Much of the data is obtained from regional stroke registries that have a male preponderance of $71-76 \%$ that is much higher than European stroke registries [22, 23].

\section{Mortality}

Reliable estimates of stroke-related mortality are available from countries of the Far East particularly China and Japan. Stroke results in $11 \%$ of all deaths among Japanese women and two thirds of these are ischemic in etiology. Similarly, stroke results in $13 \%$ of all fatalities among South Korean women with $60 \%$ being ischemic [5]. This is in sharp contrast to the 1960s when majority of the fatal strokes were hemorrhagic in nature. In a study of 47,593 women from India, men were more likely than women to die at 30 days even though they were younger in age at the time of stroke onset ( $p<0.003$; OR, 1.6; 95\% CI, 1.172.10). The mean survival time after index stroke was 10.2 months for men and 4.7 months for women survival experience in men became less favorable overtime (P 5.762; log-rank test) [24]. This is in contrast to some other studies from the same region that have reported a 30-day case fatality rate of $41.08 \%$ (men, $38.18 \%$; women, $43.24 \%$ ), with women at greater risk of dying at 30 days. The overall case fatality is significantly higher than in Western countries (17-33\%) and is likely attributable to poor awareness and lack of access to health care [10, 25]. Table 2 provides age-adjusted stroke mortality and 30-day stroke mortality among selected Asian and European countries. Mortality is high among Asian women (except Japan) as compared to European women but less when compared to Asian men.

\section{Stroke Risk Factors}

There are both conventional and gender-specific risk factors that predispose to stroke. Migraine with aura, atrial fibrillation, diabetes, hypertension and depression although not gender-specific has been found to be more prevalent in women [26].

\section{Conventional Stroke Risk Factors}

A recent study by Aljoharah et al. from Saudi Arabia demonstrated the stark increase in the prevalence of conventional stroke risk factors in women within the last decade. They report a $21.5 \%$ prevalence of diabetes mellitus as compared to $7.0 \%$ in the last decade, hypercholesterolemia at 53.2 vs. $11 \%$, isolated systolic hypertension 5.0 vs. $2.0 \%$ and increase in smoking to 7.6 vs. $0.9 \%$. Hypertension resulted in greater mortality among women than men [27].

\section{Obesity and Metabolic Syndrome}

Obesity and metabolic syndromes have also emerged as threats for ischemic stroke within the last decade. Forty-two percent of Saudi women with ischemic strokes between 2000 and 2009 met criteria for metabolic syndrome. Earlier studies from South Asia have described a twofold increase in the prevalence of metabolic syndrome and insulin resistance among women as compared to men in the last decade $[28,29]$.

\section{Oral Contraceptive Use}

The risk of stroke in women that use oral contraception varies depending on age. Among women aged 15-19, the risk is $3.4 / 100,000$ and it increases dramatically to $64.4 / 100,000$ in middle-aged women who underwent hormonal replacement therapy [30]. Due to prevailing cultural differences, oral contraceptive use is infrequent among Asian women as compared to the western world. In a recent study of 958 women with ischemic stroke in 8 Asian countries, oral contraceptive use was found to be $8 \%$ [31]. Among young women with cerebral venous sinus thrombosis, $10 \%$ were found to have used oral contraception. These rates are much lower as compared to the developed world where rates of oral contraception use vary from $35-60 \%$ [32].

\section{Addictions - Alcohol and Tobacco Use}

Alcohol and tobacco use among women is much less prevalent in Asian women as compared to women in other parts of the world. A recent population-based survey 
of 25,524 women found that only $1 \%$ of the women reported smoking. The use of smokeless tobacco comprising betel nut and tobacco leaf that is chewed was more prevalent among women as compared to men (28 vs. 21\%) [33]. Another population-based study of 1,290 women from Pakistan highlighted the use of smokeless tobacco in $4.6 \%$ of women. Only $1.8 \%$ of all women smoked tobacco. Poor socioeconomic status and lower levels of education were both found to be independently associated with tobacco use [34]. Similarly, according to present-day statistics, less than $3 \%$ of all women are reported to smoke in China [35]. Passive smoking has also been known to have a dose-response relationship with the risk for stroke. Chinese women who never smoked but were exposed to more than 20 cigarettes a day of passive smoker had twice the risk of stroke as compared to controls [36].

\section{Rheumatic Heart Disease and Atrial Fibrillation in Asian Women}

In a study of 958 women from 8 centers in 9 Asian countries, 180 (19\%) experienced cardio embolic strokes. Seventeen patients had a history of atrial fibrillation on admission and 57 of 632 (9\%) patients tested via monitoring were found to have atrial fibrillation [31]. A majority of these patients developed atrial fibrillation attributable to valvular pathology secondary to rheumatic heart disease (RHD). In all, 133 of 532 (25\%) patients in the registry who underwent an echocardiogram were diagnosed with rheumatic heart disease. Wang et al. reviewed 21 studies of patients with RHD and stroke and found that the prevalence of stroke in Asian patients with RHD ranged from 0.37 to $12.6 \%$ over the last 30 years. While $3.4-23.2 \%$ of stroke patients in Asia were found to have RHD, only $1.8-2.0 \%$ of patients in Europe and the Americas were diagnosed with RHD over the past three decades [37]. Data on gender-based differences in the incidence of stroke secondary to RHD are lacking from Asia.

\section{Migraine}

The stroke prevention in young women study highlighted a 1.5 fold higher odds of stroke (95\% CI, 1.1-2.0) in women with probably migraine with visual aura as compared to controls. This risk was further propounded in women who smoked and used oral contraception [38]. Comparable literature is lacking from Asian countries. Only $1 \%$ of young Asian women (mean age 34 years) were found to have a history of migraine among a stroke registry from 12 Asian countries.

Stroke in Women - An Asian Perspective
Dietary Factors - Anemia, Vitamin Deficiencies and

\section{Nutritional Status}

Cui et al. in their study of 35,611 Japanese women found that an increased amount of dietary folate and vitamin B6 intake was protective against mortality from stroke and coronary heart disease [39]. About 59.9\% of young Asian women with cerebral venous sinus thrombosis were found to be anemic with serum hemoglobin $<11 \mathrm{~g} / \mathrm{dl}$. This was a statistically significant result and was found to be a predictor for development of venous thrombosis $[40,41]$.

\section{Gender- and Age-Specific Risk Factors: Stroke in Young Asian Women}

Stroke in the young occurs in varying proportions among countries of the Asian region. While centers from Pakistan and India have reported rates as high as 21 and $30 \%$, studies from Taiwan and South Korea identified 7 and $10 \%$ of young stroke patients respectively $[22,23,42$, 43]. A retrospective study of stroke in young Asian women from 12 centers in eight countries found that age $>36$, diabetes, hypertension, dyslipidemia, recent myocardial infarction, electrocardiogram abnormalities and blood glucose $>150 \mathrm{mg} / \mathrm{dl}$ were stroke predictors of acute ischemic stroke. The cohort comprised of 754 patients with acute ischemic stroke and mean age was 29 . Thus, conventional risk factors continue to have heavy implications in young ischemic stroke patients as they are in the other groups [17, 40]. Recent studies from Korea have highlighted the higher incidence of atrial fibrillation among Korean women and a higher incidence of diabetes among women older than 65 years. In terms of stroke outcome, women had greater morbidity and were more likely to be dependent at 1 year after incident stroke $[44,45]$.

\section{Stroke in Pregnancy/Puerperium}

Two series of pregnancy-related stroke from Taiwan have reported a higher incidence in Asian women as compared to the West $[19,46]$. Khan et al. examined medical records of 110 women with pregnancy-related or postpartum stroke across 12 centers in 8 Asian countries. The mean age of these women was 27.94 ( $\mathrm{SD} \pm 5.78$ ), and $49.1 \%$ of these strokes were venous in etiology [47]. Postpartum state was more likely associated with venous stroke as compared to stroke of arterial etiology. Patients with venous strokes were found to have a better functional outcome as compared to arterial origin stroke.

Intracranial hemorrhage ( $\mathrm{ICH}$ ) has also been reported in pregnancy albeit infrequently in the western world. A large series of 423 pregnant patients from the United 
States reported an incidence of 6.1/100,000 [20]. A French study by Sharshar et al. demonstrated a slightly lower incidence at 4.6/100,000 [21]. Studies from Asia are in stark contrast to the above-mentioned series and have revealed a much higher incidence of ICH with estimates ranging from 10.5-31.4/100,000 deliveries [19, 48]. Hypertension and preeclampsia/eclampsia syndrome characterized by the development of high blood pressure, proteinuria with or without seizures after 20 weeks of gestation have been primarily implicated in the causation of ICH [49]. Thirtyfour percent of Pakistani and Middle-Eastern women with venous sinus thrombosis were found to have hemorrhagic stroke in a pooled database from 4 centers $[37,50]$.

\section{Eclampsia}

Tang et al. found that eclampsia resulted in stroke in $21.47 / 100,000$ deliveries in Taiwanese women. The relative risk for hemorrhagic stroke was 5.61 (95\% CI, 0.7144.10) and for ischemic stroke was 11.23 (95\% CI, 2.4551.59) from 3 days to 6 weeks postpartum with much higher rates ante partum [46]. This literature is comparable to studies from Europe and America that have demonstrated a twofold increase in the risk for stroke among women with preeclampsia/eclampsia. This risk is increased fivefold with early onset ( $<32$ weeks) of preeclampsia/eclampsia [51].

\section{Depression and Social Issues}

Depression is associated with both an increased incidence of stroke as well as poor recovery after stroke [52]. There is insufficient literature highlighting the rates of depression and its impact on stroke outcome among the Asian population especially among women.

\section{Differences in Stroke Care}

\section{Awareness and Delay in Arrival}

Lack of awareness of stroke risk factors results in delayed arrival to the hospital [40]. In a population-based structured telephone survey of Japanese adults, 23\% were able to correctly identify 5 early signs of stroke from among 10 listed symptoms with decoy choices [53]. A survey of high school students from Sargodha, Pakistan revealed a greater understanding of stroke symptoms among female students (61 vs. $30 \%$ ). However, only $23 \%$ expressed the need for calling an ambulance and rushing to the hospital [54]. A similar study from India revealed that patients in both rural and urban settings have a greater understanding of stroke symptoms, resulting in motor and sensory deficits but less so for other symptoms such as difficulty in speaking or understanding speech, head- ache and dizziness. Only $55 \%$ of the population was aware of one stroke symptom [55]. Although the literature on awareness of stroke symptoms does not provide genderbased differences, one can hypothesize that the women in several Asian countries, where rates of female education are dismal, would not be abreast of stroke symptoms.

\section{Stroke Treatment and Outcome}

Although more than twothirds of stroke occurs in the developing world, the rate of utilization of thrombolysis in Asian developing countries is extremely low, between 1 and 3\% [56]. Lack of stroke awareness, poor access to resources, financial constraints and presentation to the hospital outside the thrombolytic window limit tPa usage [57]. From 2005 to 2007, only 18 out of 1,185 stroke patients received $\mathrm{tPa}$ at an academic medical center in Pakistan. About $81 \%$ of these patients were male. The authors reported that the high proportion of men receiving tPa might be secondary to a prevailing gender bias for high-cost treatments.

Turtzo et al. comprehensively reviewed literature on stroke treatment and outcome from Europe and the United States to identify sex-based differences in stroke treatment. Women were less likely to present to a hospital within 3 hours as compared to men and were less likely to receive thrombolysis $[58,59]$.

\section{Stroke Rehabilitation}

Aggressive rehabilitation is a key player in stroke recovery. Luk et al. [60] in their study on older Chinese women undergoing rehabilitation demonstrated a better functional outcome, but a poor motor outcome in women on discharge from rehabilitation. Men had better recovery than women in climbing stairs and in activities of daily living after an index stroke according to the findings of an Italian case-control study by Paolucci and colleagues [61]. Gender and cost bias are prevalent particularly within low-income countries and may be responsible for poor access to rehabilitation for women. Further studies are needed to elucidate differences in stroke recovery in Asian women.

\section{Limitations}

Our review has several limitations. The studies reviewed were mostly retrospective and not powered to detect gender-based differences. In addition, several stroke registries had a greater number of males that likely represents a gender bias in access to health care. Outcome and recovery data were not readily available and further studies are needed in this area. 


\section{Future Directions}

Our review exposes the gaps in our knowledge about stroke risk factors and differences in stroke care provided to Asian women. While there are socio-cultural barriers that impede the provision of immediate care to these stroke patients, much needs to be done by way of prevention of recurrent stroke and treatment of risk factors. We think that the burden of stroke in Asian women has to be dealt with in a multi-tiered fashion by utilizing a systematic approach. There is an imminent need for (1) well-conducted, appropriately powered, prospective clinical studies that record demographic and outcome data for female patients with acute ischemic stroke, (2) spread of stroke education particularly among women of lower socio-economic strata using specific literacy-based approaches and (3) improvement in the rate of stroke thrombolysis by improving prehospital emergency systems and early arrival to the hospitals. Further research needs to be done in Asian women to determine the impact of quality interventions in stroke care.

\section{Disclosure Statement}

None declared.

\section{References}

$\checkmark 1$ Feigin VL, Forouzanfar MH, Krishnamurthi R, Mensah GA: Global burden of stroke: an underestimate - authors' reply. Lancet 2014; 383:1205-1206.

2 Lozano R, Naghavi M, Foreman K, Lim S, Shibuya K, Aboyans V, et al: Global and regional mortality from 235 causes of death for 20 age groups in 1990 and 2010: a systematic analysis for the global burden of disease study 2010. Lancet 2012;380:2095-2128.

-3 Murray CJ, Ezzati M, Flaxman AD, Lim S, Lozano R, Michaud C, et al: GBD 2010: a multiinvestigator collaboration for global comparative descriptive epidemiology. Lancet 2012; 380:2055-2058.

4 Prasad K, Vibha D, Meenakshi: Cerebrovascular disease in South Asia - Part I: a burning problem. JRSM Cardiovasc Dis 2012; 1:cvd.2012.012025.

5 Woodward M, Tsukinoki-Murakami R, Murakami Y, Suh I, Fang X, Ueshima H, et al: The epidemiology of stroke amongst women in the Asia-Pacific region. Womens Health (Lond Engl) 2011;7:305-317.

-6 Vibha, Laskar AR: Women's health: beyond reproductive years. Indian J Public Health 2011;55:247-251.

7 Johnston SC, Mendis S, Mathers CD: Global variation in stroke burden and mortality: estimates from monitoring, surveillance, and modelling. Lancet Neurol 2009;8:345354.

8 Lewsey JD, Gillies M, Jhund PS, Chalmers JW, Redpath A, Briggs A, et al: Sex differences in incidence, mortality, and survival in individuals with stroke in Scotland, 1986 to 2005 . Stroke 2009;40:1038-1043.

$\rightarrow 9$ Haast RA, Gustafson DR, Kiliaan AJ: Sex differences in stroke. J Cereb Blood Flow Metab 2012;32:2100-2107.

10 Das SK, Banerjee TK, Biswas A, Roy T, Raut DK, Mukherjee CS, et al: A prospective community-based study of stroke in Kolkata, India. Stroke 2007;38:906-910.
11 Banerjee TK, Mukherjee CS, Sarkhel A: Stroke in the urban population of Calcutta an epidemiological study. Neuroepidemiology 2001;20:201-207.

12 Thorvaldsen P, Kuulasmaa K, Rajakangas AM, Rastenyte D, Sarti C, Wilhelmsen L: Stroke trends in the WHO MONICA project. Stroke 1997;28:500-506

13 Jiang B, Wang WZ, Chen H, Hong Z, Yang $\mathrm{QD}, \mathrm{Wu} \mathrm{SP}$, et al: Incidence and trends of stroke and its subtypes in China: results from three large cities. Stroke 2006;37:63-68.

14 Zhang LF, Yang J, Hong Z, Yuan GG, Zhou BF, Zhao LC, et al: Proportion of different subtypes of stroke in China. Stroke 2003;34: 2091-2096.

15 Ahangar AA, Ashraf Vaghefi SB, Ramaezani $M$ : Epidemiological evaluation of stroke in Babol, northern Iran (2001-2003). Eur Neurol 2005;54:93-97.

16 Oveisgharan S, Sarrafzadegan N, Shirani S, Hosseini S, Hasanzadeh P, Khosravi A: Stroke in Isfahan, Iran: hospital admission and 28day case fatality rate. Cerebrovasc Dis 2007; 24:495-499.

17 O’Donnell MJ, Xavier D, Liu L, Zhang H, Chin SL, Rao-Melacini P, et al: Risk factors for ischaemic and intracerebral haemorrhagic stroke in 22 countries (the INTERSTROKE study): a case-control study. Lancet 2010;376: 112-123.

18 Panagariya A, Garg A, Sureka RK: Antiphospholipid antibody positive young stroke: an analysis of 12 cases. J Postgrad Med 2000;46: 258-261.

19 Jeng JS, Tang SC, Yip PK: Incidence and etiologies of stroke during pregnancy and puerperium as evidenced in Taiwanese women. Cerebrovasc Dis 2004;18:290-295.

20 Bateman BT, Schumacher HC, Bushnell CD, Pile-Spellman J, Simpson LL, Sacco RL, et al: Intracerebral hemorrhage in pregnancy: frequency, risk factors, and outcome. Neurology 2006;67:424-429.
21 Sharshar T, Lamy C, Mas JL: Incidence and causes of strokes associated with pregnancy and puerperium. A study in public hospitals of Ile de France. Stroke in pregnancy study group. Stroke 1995;26:930-936.

22 Lee TH, Hsu WC, Chen CJ, Chen ST: Etiologic study of young ischemic stroke in Taiwan. Stroke 2002;33:1950-1955.

23 Kwon SU, Kim JS, Lee JH, Lee MC: Ischemic stroke in Korean young adults. Acta Neurol Scand 2000;101:19-24.

24 Ray BK, Hazra A, Ghosal M, Banerjee T, Chaudhuri A, Singh V, et al: Early and delayed fatality of stroke in Kolkata, India: results from a 7-year longitudinal population-based study. J Stroke Cerebrovasc Dis 2013;22:281-289.

25 Brown RD, Whisnant JP, Sicks JD, O'Fallon WM, Wiebers DO: Stroke incidence, prevalence, and survival: secular trends in Rochester, Minnesota, through 1989. Stroke 1996;27: 373-380.

26 Bushnell C, McCullough LD, Awad IA, Chireau MV, Fedder WN, Furie KL, et al: Guidelines for the prevention of stroke in women: a statement for healthcare professionals from the American Heart Association/American Stroke Association. Stroke 2014;45:1545-1588.

27 Alquaiz AM, Siddiqui AR, Qureshi RH, Fouda MA, Al Muneef MA, Habib FA, et al: Women health in Saudi Arabia: a review of non-communicable diseases and their risk factors. Pak J Med Sci 2014;30:422-431.

28 Gupta R, Deedwania PC, Gupta A, Rastogi S, Panwar RB, Kothari K: Prevalence of metabolic syndrome in an Indian urban population. Int J Cardiol 2004;97:257-261.

29 Misra A, Khurana L: The metabolic syndrome in South Asians: epidemiology, determinants, and prevention. Metab Syndr Relat Disord 2009;7:497-514.

30 Lidegaard Ø, Løkkegaard E, Jensen A, Skovlund CW, Keiding N: Thrombotic stroke and myocardial infarction with hormonal contraception. N Engl J Med 2012;366:2257-2266. 
-31 Wasay M, Kaul S, Menon B, Venketasubramanian N, Gunaratne P, Khalifa A, et al: Ischemic stroke in young Asian women: risk factors, subtypes and outcome. Cerebrovasc Dis 2010;30:418-422.

32 Martinelli I, Sacchi E, Landi G, Taioli E, Duca F, Mannucci PM: High risk of cerebral-vein thrombosis in carriers of a prothrombin-gene mutation and in users of oral contraceptives. N Engl J Med 1998;338:1793-1797.

33 Hoque ME, Khan JA, Hossain SS, Gazi R, Rashid HA, Koehlmoos TP, et al: A systematic review of economic evaluations of health and health-related interventions in Bangladesh. Cost Eff Resour Alloc 2011;9:12.

34 Gilani SI, Leon DA: Prevalence and sociodemographic determinants of tobacco use among adults in Pakistan: findings of a nationwide survey conducted in 2012. Popul Health Metr 2013;11:16.

- 35 Wang L, Kong L, Wu F, Bai Y, Burton R: Preventing chronic diseases in China. Lancet 2005;366:1821-1824.

-36 He Y, Lam TH, Jiang B, Wang J, Sai X, Fan L, et al: Passive smoking and risk of peripheral arterial disease and ischemic stroke in Chinese women who never smoked. Circulation 2008 118:1535-1540.

37 Wang D, Liu M, Lin S, Hao Z, Tao W, Chen $\mathrm{X}$, Luan R, Dong W: Stroke and rheumatic heart disease: a systematic review of observational studies. Clin Neurol Neurosurg 2013; 115:1575-1582.

38 MacClellan LR, Giles W, Cole J, Wozniak M, Stern B, Mitchell BD, et al: Probable migraine with visual aura and risk of ischemic stroke: the stroke prevention in young women study. Stroke 2007;38:2438-2445.

- 39 Cui R, Iso H, Date C, Kikuchi S, Tamakoshi A: Dietary folate and vitamin B6 and B12 intake in relation to mortality from cardiovascular diseases: Japan collaborative cohort study. Stroke 2010;41:1285-1289.

40 Wasay M, Khealani B, Yousuf A, Azam I, Rathi SL, Malik A, et al: Knowledge gaps in stroke care: results of a survey of family physicians in Pakistan. J Stroke Cerebrovasc Dis 2011;20:282-286.

41 Wasay M, Saadatnia M, Venketasubramanian N, Kaul S, Menon B, Gunaratne P, et al: Predictors of cerebral venous thrombosis and arterial ischemic stroke in young Asian women. J Stroke Cerebrovasc Dis 2012;21:689-694.

$\checkmark 42$ Anand K, Chowdhury D, Singh KB, Pandav CS, Kapoor SK: Estimation of mortality and morbidity due to strokes in India. Neuroepidemiology 2001;20:208-211.
43 Nayak SD, Nair M, Radhakrishnan K, Sarma PS: Ischaemic stroke in the young adult: clinical features, risk factors and outcome. Natl Med J India 1997;10:107-112.

44 Park TH, Ko Y, Lee SJ, Lee KB, Lee J, Han MK, et al: Gender differences in the age-stratified prevalence of risk factors in Korean ischemic stroke patients: a nationwide stroke registrybased cross-sectional study. Int J Stroke 2014; 9:759-765.

45 Mehndiratta MM, Khan M, Mehndiratta P, Wasay M: Stroke in Asia: geographical variations and temporal trends. J Neurol Neurosurg Psychiatry 2014;85:1308-1312.

46 Tang CH, Wu CS, Lee TH, Hung ST, Yang $\mathrm{CY}$, Lee $\mathrm{CH}$, et al: Preeclampsia-eclampsia and the risk of stroke among peripartum in Taiwan. Stroke 2009;40:1162-1168.

47 Khan M, Wasay M, Menon B, Saadatnia M, Venketasubramanian N, Gunaratne P, et al: Pregnancy and puerperium-related strokes in Asian women. J Stroke Cerebrovasc Dis 2013; 22:1393-1398.

48 Liang CC, Chang SD, Lai SL, Hsieh CC, Chueh HY, Lee TH: Stroke complicating pregnancy and the puerperium. Eur J Neurol 2006;13: 1256-1260.

49 Martin JN Jr, Thigpen BD, Moore RC, Rose $\mathrm{CH}$, Cushman J, May W: Stroke and severe preeclampsia and eclampsia: a paradigm shift focusing on systolic blood pressure. Obstet Gynecol 2005; 105:246-254.

50 Khealani BA, Wasay M, Saadah M, Sultana E, Mustafa S, Khan FS, et al: Cerebral venous thrombosis: a descriptive multicenter study of patients in Pakistan and Middle East. Stroke 2008;39:2707-2711.

51 McDonald SD, Malinowski A, Zhou Q, Yusuf S, Devereaux PJ: Cardiovascular sequelae of preeclampsia/eclampsia: a systematic review and meta-analyses. Am Heart J 2008; 156 : 918-930.

- 52 Hackett ML, Yapa C, Parag V, Anderson CS Frequency of depression after stroke: a systematic review of observational studies. Stroke 2005;36:1330-1340.

53 Miyamatsu N, Okamura T, Nakayama H, Toyoda K, Suzuki K, Toyota A, et al: Public awareness of early symptoms of stroke and information sources about stroke among the general Japanese population: the acquisition of stroke knowledge study. Cerebrovasc Dis 2013;35:241-249.

54 Farooq MU, Bhatt A, Safdar A, Kassab MY, Majid A: Stroke symptoms and risk factor awareness in high school children in Pakistan. Int J Stroke 2012;7:E15.
55 Pandian JD, Jaison A, Deepak SS, Kalra G, Shamsher S, Lincoln DJ, et al: Public awareness of warning symptoms, risk factors, and treatment of stroke in northwest India. Stroke 2005;36:644-648.

56 Pandian JD: Stroke and thrombolysis in India. Neurol India 2007;55:173; author reply 173-174.

57 Wasay M, Azeemuddin M, Masroor I, Sajjad Z, Ahmed R, Khealani BA, et al: Frequency and outcome of carotid atheromatous disease in patients with stroke in Pakistan. Stroke 2009;40:708-712.

58 Foerch C, Misselwitz B, Humpich M, Steinmetz H, Neumann-Haefelin T, Sitzer M: Sex disparity in the access of elderly patients to acute stroke care. Stroke 2007;38:2123-2126.

59 Gargano JW, Wehner S, Reeves M: Sex differences in acute stroke care in a statewide stroke registry. Stroke 2008;39:24-29.

60 Luk JK, Cheung RT, Ho SL, Li L: Does age predict outcome in stroke rehabilitation? A study of 878 Chinese subjects. Cerebrovasc Dis 2006;21:229-234.

61 Paolucci S, Bragoni M, Coiro P, De Angelis D, Fusco FR, Morelli D, et al: Is sex a prognostic factor in stroke rehabilitation? A matched comparison. Stroke 2006;37:2989-2994.

62 The European Registers of Stroke (EROS) Investigators, Heuschmann PU, Di Carlo A, et al: Incidence of stroke in Europe at the beginning of the 21st century. Stroke 2009;40: 1557-1563.

63 Béjot Y, Osseby GV, Aboa-Eboulé C, et al: Dijon's vanishing lead with regard to low incidence of stroke. Eur J Neurol 2009;16:324329 .

64 Corso G, Bottacchi E, Giardini G, et al: Community-based study of stroke incidence in the valley of Aosta, Italy. CARe-cerebrovascular Aosta registry: years 2004-2005. Neuroepidemiology 2009;32:186-195.

65 Sridharan SE, Unnikrishnan JP, Sukumaran $S$, et al: Incidence, types, risk factors, and outcome of stroke in a developing country: the Trivandrum stroke registry. Stroke 2009;40: 1212-1218

-66 Thrift AG, Cadilhac DA, Thayabaranathan T, Howard G, Howard VI, Rothwell PM, Donnan GA: Global stroke statistics. Int J Stroke 2014;9:6-18.

-67 Wu GX, Wu ZS, He BL: [Epidemiological characteristics of stroke in 16 provinces of China]. Zhonghua Yi Xue Za Zhi 1994;74: 281-283, 325.

68 State of the Nation: Stroke statistics, January 2015. www.stroke.org.uk. 